\title{
PEO coatings with active protection based on in-situ formed LDH- nanocontainers
}

\author{
M. Serdechnova ${ }^{1}$, M. Mohedano ${ }^{1}$, B. Kuznetsov ${ }^{2}$, C.L. Mendis ${ }^{1}$, M. Starykevich ${ }^{3}$, S.

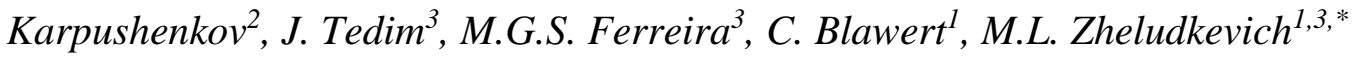 \\ ${ }^{1}$ Institute of Materials Research, Helmholtz-Zentrum Geesthacht, Max-Planck-Straße 1, 21502 Geesthacht, \\ Germany \\ ${ }^{2}$ Belarusian State University, Faculty of Chemistry, 4, Nezavisimosti avenue, 220030, Minsk, Belarus \\ ${ }^{3}$ Department of Materials and Ceramic Engineering, CICECO - Aveiro Institute of Materials, University of Aveiro, \\ 3810-193 Aveiro, Portugal
}

\begin{abstract}
In the present work, for the first time $\mathrm{Zn}-\mathrm{Al}$ layered double hydroxide (LDH) nanocontainers were grown in-situ on the surface and in the pores of plasma electrolytic oxidation (PEO) layer and then loaded with a corrosion inhibitor to provide an active protection. The developed LDHbased conversion process ensures partial sealing of the pores and provides an effective corrosion inhibition on demand leading to increased fault-tolerance and self-healing properties. The structure, morphology and composition of the LDH-sealed PEO coatings on 2024 aluminum alloy were investigated using SEM, TEM/FIB, XRD and GDOES. Electrochemical impedance spectroscopy and scanning vibrating electrode techniques show a remarkable increase in the corrosion resistance and fault tolerance when PEO coating is sealed with a LDH-inhibitor treatment.
\end{abstract}

\section{Keywords}

AA2024; Plasma electrolytic oxidation; Layered double hydroxides; Corrosion inhibitor;

*Corresponding author: Prof. Mikhail Zheludkevich, mikhail.zheludkevich@hzg.de 


\section{Highlights}

$\mathrm{Zn}-\mathrm{Al}$ LDH was grown on PEO treated 2024 aluminum alloy using a conversion process

The loading of vanadate into LDH nanocontainers is achieved via an anionic exchange reaction

The in-situ grown LDH-nanocontainers confer remarkable active corrosion protection and increased fault-tolerance to the PEO coatings 


\section{Introduction}

Plasma electrolytic oxidation (PEO) is an advanced anodizing process which leads to the formation of ceramic-like coatings on the surface of many light alloys. The coatings form on the surface as a result of short-lived micro-discharges at high voltages in low-concentrated ecofriendly electrolytes $\left[{ }^{1}\right]$. The oxide layers developed by PEO are usually hard, strongly-adherent to the substrate and confer both corrosion and wear resistance $\left[{ }^{2}\right]$.The properties of PEO layers can be tuned for various applications such as biomedical, photocatalytic, thermal and decorative playing with composition of electrolytes and electrical parameters $\left[{ }^{3},{ }^{4}, 5\right]$. In spite of many advantages, the PEO coatings are usually composed of relatively porous layers as a result of discharge breakdowns and gas evolution during the coating growth. Such an intrinsic porosity of the layer often compromises the barrier properties of even relatively thick coatings. Moreover, thicker is the coating larger are the pores in many cases. Several attempts have been made to reduce or seal such porosity. Optimization of current/voltage regimes $\left[{ }^{6,7}\right]$, changing the electrolyte composition including systems with particles $\left[{ }^{8}, 9\right]$, different post-treatments $\left[{ }^{10,11}\right]$ and duplex coatings $\left[{ }^{12,13}\right]$ were tried among other strategies. However, in spite of offering certain improvement to the barrier properties none of these approaches ensures an active protection. Without the active protection the acceptance of PEO coatings for many high demanding applications such as aeronautics is limited. In previous works, a post-treatment immersion of PEO coated $\mathrm{Mg}$ alloys into inhibitor containing solution was tried to achieve the active protection. $\mathrm{Ce}^{3+}\left[{ }^{14}\right]$ and 8-hydroxyquinoline $\left[{ }^{15}\right]$ were used as corrosion inhibitors. Certain active protection effect was reported though the important issues related to uncontrollable release of inhibiting species were not considered.

Recently, layered double hydroxides (LDH) have been widely investigated as environmentallyfriendly containers for active corrosion protection of metals, in the form of conversion films $\left[{ }^{16},{ }^{17},{ }^{18},{ }^{19}\right]$ and as inhibiting pigments being incorporated into the polymer coatings $\left[{ }^{20}\right]$. The LDH particles offer a twofold effect absorbing excess of chloride anions from the corrosive environment and releasing the corrosion inhibitors on demand $\left[{ }^{21},{ }^{22},{ }^{23}\right]$. The release of incorporated inhibitors can also be triggered by local increase of $\mathrm{pH}$ at cathodic sites $\left[{ }^{24},{ }^{25}\right]$. Typically LDHs are composed by positively-charged mixed metal $M^{\mathrm{II}}-M^{\mathrm{III}}$ hydroxide layers and interlayers filled by the charge compensating anions $\left(A^{y-}\right)$ and $\mathrm{H}_{2} \mathrm{O}$ molecules $\left[{ }^{26}\right]$. The general formula for the most common LDHs is $\left[M^{\mathrm{II}}{ }_{1-x} M^{\mathrm{III}}{ }_{x}(\mathrm{OH})_{2}\right]^{x+}\left(A^{y-}\right)_{x / y} \cdot z \mathrm{H}_{2} \mathrm{O}\left[{ }^{27,28}\right]$.

In several recent studies, LDH films were prepared on bare aluminum alloys as a result of conversion process $\left[{ }^{29},{ }^{30}\right]$ to provide an additional active protection. The aluminum substrate was immersed in a $\mathrm{M}^{2+}$ containing solution leading to the formation of the LDH film, containing 
$\mathrm{M}^{2+}$ and $\mathrm{Al}^{3+}$. The LDH layer was successfully loaded with a corrosion inhibitor via anionexchange process forming a nano-structured layer next to the metal surface $\left[{ }^{31},{ }^{32}\right]$. The application of LDH-based conversion process for sealing the pores in a TSA anodic layer on aluminum was also reported in a recent work $\left[{ }^{33}\right]$. In this case the LDH structures are formed in the pores of anodic layer and on its surface. The barrier properties of the anodic coating are drastically improved similarly to the hot-water sealing but an active protection effect is also additionally achieved when vanadate anions are placed between the LDH layers via an ionexchange reaction. The superior performance of such a sealing process was demonstrated in accelerated corrosion tests and using electrochemical methods.

In the present work for the first time we propose an inhibitor-containing LDH-based post treatment for sealing the PEO layers aiming at additional active protection acting on demand and improved barrier properties. For this purpose the PEO treated AA2024 aluminum alloy was sealed with $\mathrm{Zn}-\mathrm{Al} \mathrm{LDH}$ and vanadate as an inhibitor (with possible efficiency of almost $100 \%$ in comparison with chromate treatment $\left[{ }^{34}\right]$ ) was intercalated into the LDH galleries. This system was chosen as a model one for the aluminum protection, due to the combination of effective barrier properties, provided by PEO layer, and active protection, provided by LDH with inhibitor. The structure, morphology and properties of the PEO-LDH layer were investigated using diffraction and microscopic techniques, while the active corrosion protection and increased fault tolerance were studied by combination of integral and localized electrochemical techniques.

\section{Experimental}

\subsection{Chemicals}

The chemicals used in this work are: zinc nitrate hexahydrate $\left(\mathrm{Zn}\left(\mathrm{NO}_{3}\right)_{2} \cdot 6 \mathrm{H}_{2} \mathrm{O},>99 \%\right.$, CarlRoth, Germany), ammonium nitrate $\left(\mathrm{NH}_{4} \mathrm{NO}_{3},>98.5 \%\right.$, Bernd Kraft, Germany), ammonia solution $\left(\mathrm{NH}_{3} \mathrm{H}_{2} \mathrm{O}, 25 \%\right.$, Merck KGaA, Germany), sodium vanadium oxide $\left(\mathrm{NaVO}_{3}, 96 \%\right.$, AlfaAesar, Germany), sodium metasilicate $\left(\mathrm{Na}_{2} \mathrm{SiO}_{3}, 44-47 \% \mathrm{SiO}_{2}\right.$, Sigma-Aldrich Chemie $\mathrm{GmbH}$, Germany), sodium hydroxide $(\mathrm{NaOH},>99 \%$, Merck KGaA, Germany), sodium dihydrogen phosphate $\left(\mathrm{Na}_{2} \mathrm{H}_{2} \mathrm{P}_{2} \mathrm{O}_{7}, 98 \%\right.$, Chempur, Germany), nitric acid $\left(\mathrm{HNO}_{3}, 65 \%\right.$, Merck $\mathrm{KGaA}$, Germany) and sodium chloride ( $\mathrm{NaCl}, 99.98 \%$, Fisher Chemical, UK). The solvent was deionized water.

\subsection{Specimens preparation}

The used substrate was 2024-T3 aluminum alloy with a nominal composition in wt.\% : 3.8-4.9 $\mathrm{Cu}, 0.5 \mathrm{Fe}, 0.1 \mathrm{Cr}, 1.2-1.8 \mathrm{Mg}, 0.3-0.9 \mathrm{Mn}, 0.5 \mathrm{Si}, 0.15 \mathrm{Ti}, 0.25 \mathrm{Zn}, 0.15$ others and Al balance. 
The samples were cut from sheets into $20 \mathrm{~mm} \times 30 \mathrm{~mm} \times 2 \mathrm{~mm}$ coupons. Prior to the PEO processing, specimens were etched in $20 \mathrm{wt} . \%$ sodium hydroxide solution for $60 \mathrm{~s}$, rinsed in deionized water, desmutted in $65 \mathrm{wt} . \%$ nitric acid solution for $60 \mathrm{~s}$, rinsed in deionized water again and, finally, dried with warm air.

The PEO processing was conducted at a constant voltage of $400 \mathrm{~V}$ for $15 \mathrm{~min}$ using a pulsed DC power supply with a pulse ratio of $t_{o n}: t_{o f f}=1 \mathrm{~ms}: 9 \mathrm{~ms}$ and a current density limit of $70 \mathrm{~mA} \mathrm{~cm} \mathrm{~cm}^{-2}$ (rms). The electrolyte, containing $9 \mathrm{~g} \mathrm{~L}^{-1} \mathrm{Na}_{2} \mathrm{SiO}_{3}, 2 \mathrm{~g} \mathrm{~L}^{-1} \mathrm{NaOH}$ and $11 \mathrm{~g} \mathrm{~L}^{-1} \mathrm{Na}_{2} \mathrm{H}_{2} \mathrm{P}_{2} \mathrm{O}_{7}$ dissolved in deionized water (methodology adopted from $\left[{ }^{35},{ }^{36}\right]$ ), was continuously stirred during the treatment and kept at $20 \pm 2{ }^{\circ} \mathrm{C}$ by a water cooling system. The counter-electrode was made of stainless steel. After PEO treatment, the specimens were rinsed in deionized water and dried in warm air.

$\mathrm{Zn}-\mathrm{Al} \mathrm{LDH}-$ nitrate $\left(\mathrm{LDH}-\mathrm{NO}_{3}\right)$ were grown on the surface of PEO covered AA2024 using the methodology adapted from the previous work on sealing TSA anodized aluminum $\left[{ }^{33}\right]$. Briefly, $\mathrm{Zn}\left(\mathrm{NO}_{3}\right)_{2} \cdot 6 \mathrm{H}_{2} \mathrm{O}(0.01 \mathrm{~mol})$ and $\mathrm{NH}_{4} \mathrm{NO}_{3}(0.06 \mathrm{~mol})$ were dissolved in deionized water $(100 \mathrm{ml})$; then the $\mathrm{pH}$ of the solution was adjusted to 6.5 by drop wise addition of $1 \%$ ammonia. The specimens were immersed in the solution at $95^{\circ} \mathrm{C}$ for 30 minutes under continuous stirring then rinsed in deionized water and dried in air at room temperature.

The inhibitor loading was performed by anion-exchange reaction between the nitrate from LDH galleries and vanadate from the solution. For the anion-exchange reaction $0.1 \mathrm{M} \mathrm{NaVO}_{3}$ solution $\left(\mathrm{pH}\right.$ 8.4) was prepared. The specimens coated with $\mathrm{PEO}$ and sealed with $\mathrm{LDH}_{-} \mathrm{NO}_{3}$ were immersed in this solution at $50^{\circ} \mathrm{C}$ for $30 \mathrm{~min}$. After the exchange, the samples were rinsed with deionized water and dried at room temperature in air. The product of anionic-exchange reaction between $\mathrm{LDH}-\mathrm{NO}_{3}$ and vanadate in obtained and called $\mathrm{LDH}-\mathrm{VO}_{\mathrm{x}}$ in frame of this work. Its structure and properties for active corrosion properties for PEO covered AA2024 are further discussed.

\subsection{Techniques}

Tescan Vega3 SB scanning electron microscope (SEM) equipped with energy dispersive X-ray (EDX) spectrometer, operating at $17 \mathrm{kV}$ was used to evaluate morphology and composition of the coatings. Cross-sections were prepared using standard metallographic techniques.

Crystalline phases formed during PEO and LDH sealing were characterized using a PANalytical X'Pert Powder diffractometer (XRD, Ni-filtered $\mathrm{Cu} \mathrm{K} \alpha$ radiation, step size $0.02^{\circ}$, dwell time $\sim 1.5 \mathrm{~s}$ ) at room temperature. 
Transmission electron microscopy (TEM) was carried out using FEI CM200 microscope operating at $200 \mathrm{kV}$. The cross-section specimens for TEM were prepared using focused ion beam (FIB) milling as described elsewhere $\left[{ }^{37}\right]$. Glow discharge optical emission spectroscopy (GDOES) was used to analyze the coating composition profile across the formed coating layers (HORIBA GD-Profiler 2 with an anode of $4 \mathrm{~mm}$ in diameter).

Electrochemical impedance spectroscopy (EIS) was conducted in a stirred $0.5 \mathrm{wt} . \% \mathrm{NaCl}$ solution at $22 \pm 0.5^{\circ} \mathrm{C}$ using a Gill AC computer-controlled potentiostat. All potentials were measured against a $\mathrm{Ag} / \mathrm{AgCl}$ reference electrode ( $3 \mathrm{M} \mathrm{KCl}$ as internal electrolyte) and a platinum mesh as the counter electrode. The measurements were conducted after different immersion times with a sinusoidal perturbation of $10 \mathrm{mV}$ RMS and a frequency sweep from $30 \mathrm{kHz}$ to $0.01 \mathrm{~Hz}$. For all measurements the coated specimen served as the working electrode with an exposed area of $0.5 \mathrm{~cm}^{2}$. The measurements were repeated at least twice to ensure reproducibility. ZView software was used for the analysis of impedance spectra (goodness of fit $\chi^{2}<0.01$ ). The errors for the individual parameters of the equivalent electrical circuits (such as $\mathrm{CPE}$ and $\mathrm{R})$ were $<5 \%$.

Scanning vibrating electrode technique (SVET) measurements were performed using Applicable Electronics Inc. (USA) instrument controlled with the ASET-LV4 software from ScienceWares (USA). The experimental details of the technique are described elsewhere $\left[{ }^{33}\right]$. The QuickGrid (version 1.2) free software was used for the SVET map analysis.

\section{Results and discussion}

\section{$\underline{\text { PEO coating characterization and } \mathrm{LDH} \text { formation }}$}

The cross-sectional BSE (back-scattered electrons) micrograph and X-ray diffraction patterns of a typical PEO coating formed on AA2024 are demonstrated in Fig.1. It can be seen that the layer has relatively non-uniform thickness in the range of 3-6 $\mu \mathrm{m}$. The coating is mainly composed by amorphous and $\mathrm{\gamma}-\mathrm{Al}_{2} \mathrm{O}_{3}$ (Fig. $\mathbf{1}(\mathbf{b})$ ) in agreement with previously reported $\left[{ }^{38},{ }^{39}\right]$ and consists of a typical PEO structure with an inner denser barrier layer followed by a more porous outer layer with through going discharge channels. 


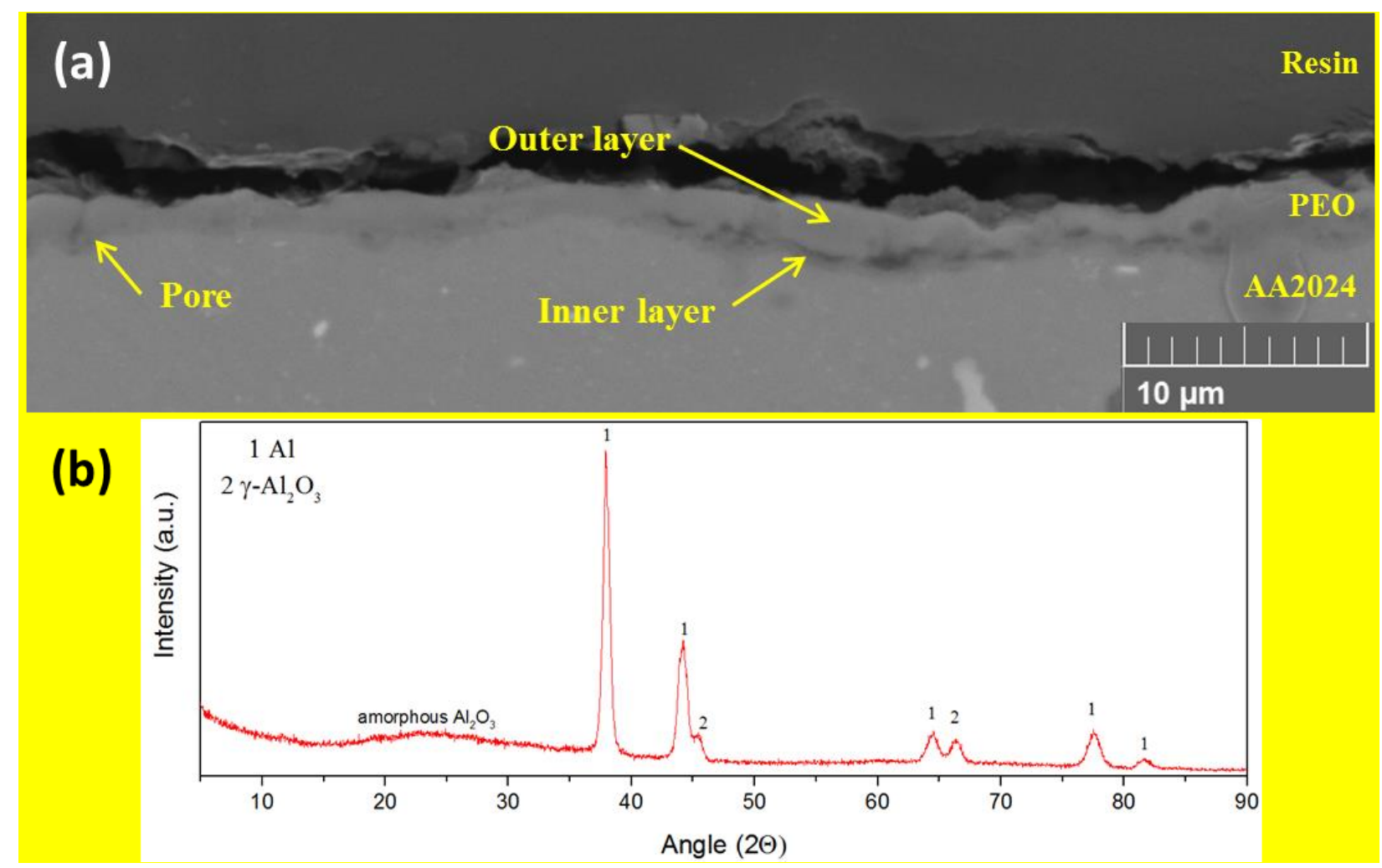

Fig. 1. Backscattered electron images of the cross section (a) and XRD pattern of PEO coated AA2024 aluminum alloy (a).

The SEM micrographs (top view) of the PEO coating on the surface of AA2024 aluminum alloy (PEO sample), PEO sample with $\mathrm{LDH}-\mathrm{NO}_{3}$ and PEO sample with $\mathrm{LDH}-\mathrm{VO}_{\mathrm{x}}$ modification are shown in Fig. 2. 

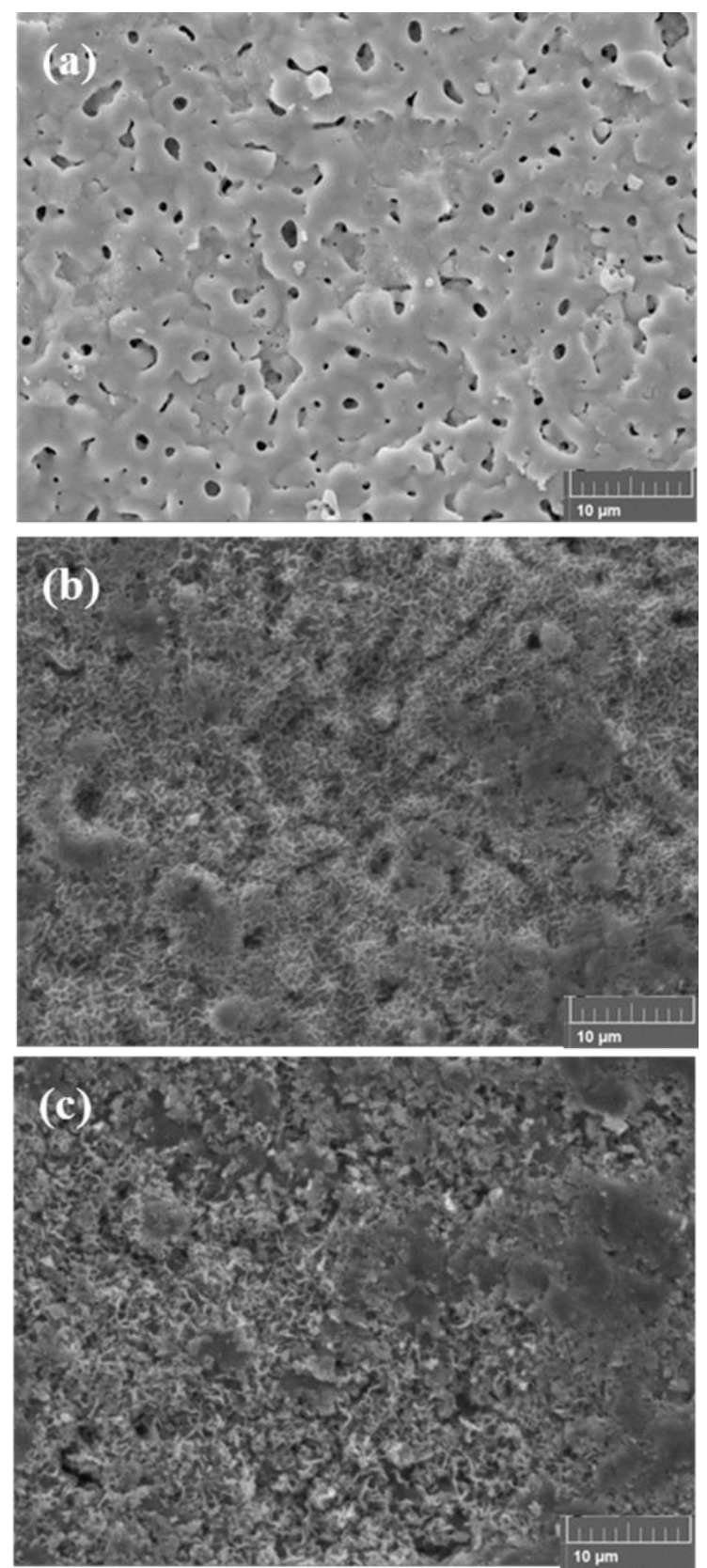

Fig. 2. SEM micrographs of PEO sample (a), $\mathrm{PEO}$ with $\mathrm{LDH}-\mathrm{NO}_{3}(b)$ and $\mathrm{PEO}$ with $\mathrm{LDH}-\mathrm{VO}_{x}(\mathrm{c})$.

The PEO sample (Fig. 2a) shows the typical surface morphology of plasma electrolytic oxidation layers with pores and some micro-cracks on the surface at the sites of the discharge channels, due to the gas evolution through the molten oxide material during the PEO process and thermal stresses, respectively $\left[^{1}\right]$. The surface appearance significantly changes after the LDH sealing treatment. A dense layer of flakes covers the PEO coating (Fig. 2b). The flake-like morphology persists after the loading of LDH with vanadates anions (Fig. 2c).

The distribution of the main elements (Al from the alloy, P and Si from the PEO coating, $\mathrm{Zn}$ and $\mathrm{V}$ from LDH treatment) was characterized with a qualitatively EDX elemental mapping using $\mathrm{K}_{\mathrm{a}}$ lines (Fig. 3). 


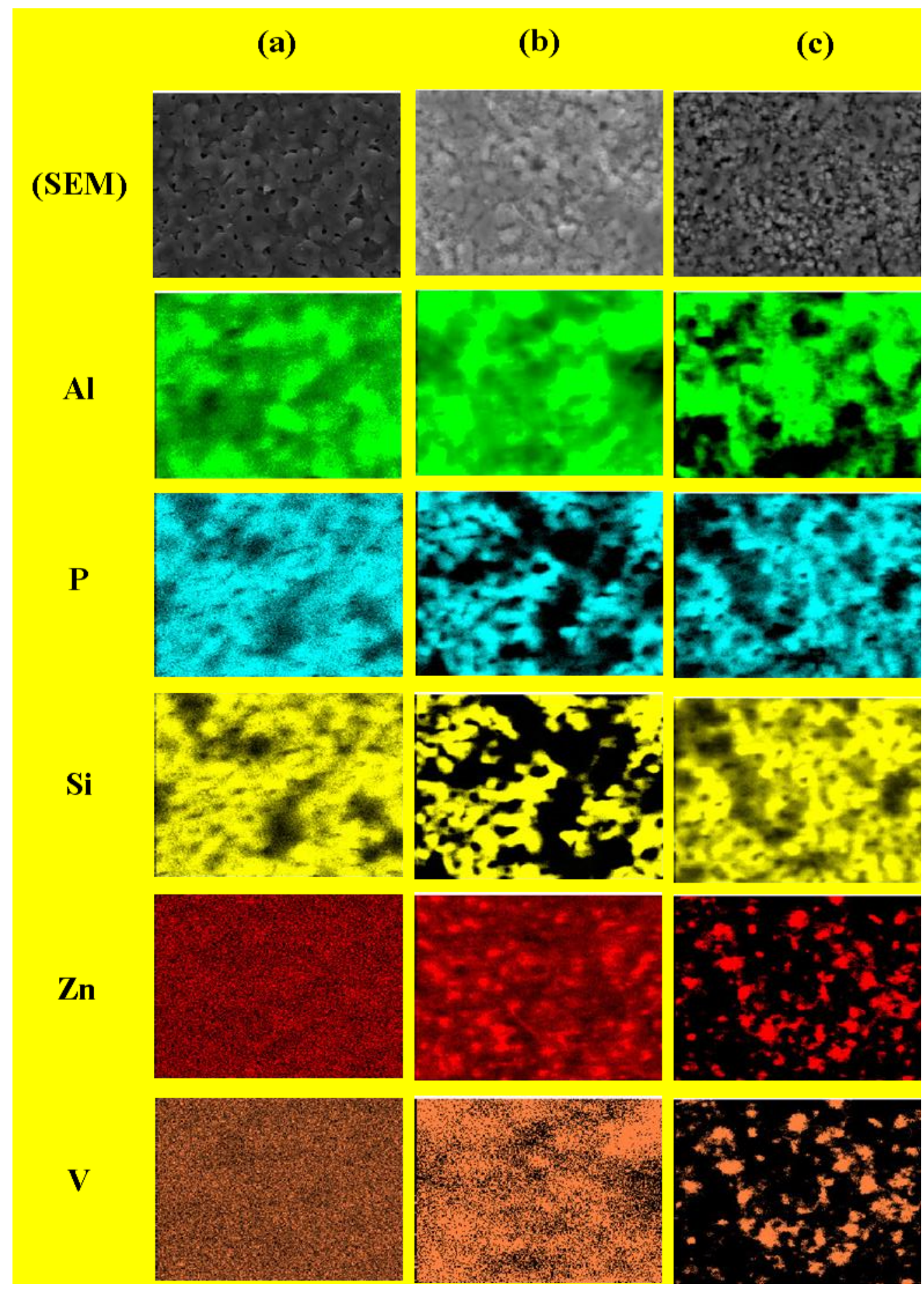

Fig. 3. Distribution of pertinent elements for $\mathrm{PEO}$ sample (a), $\mathrm{PEO}$ sample with $\mathrm{LDH}-\mathrm{NO} \mathrm{O}_{3}(\mathrm{~b})$ and $\mathrm{PEO}$ sample with $\mathrm{LDH}-\mathrm{VO}_{x}(\mathrm{c})$.

The elemental distributions show (Fig. 3a) that PEO coating is enriched with phosphorus and silicon (with ratio of 0.45 ) from the electrolyte solution. Zinc and vanadium are not detected on the surface of this sample. The low intensity uniform contrast is due to the background noise. For the PEO sample treated with $\mathrm{LDH}-\mathrm{NO}_{3}$ a clear distribution of $\mathrm{Zn}$ can be observed at locations were strong formation of flakes occurs (Fig. 3b). The LDH distribution is not uniform and is more concentrated in the regions containing defects in the PEO coating. The sample subjected to anion-exchange clearly evidences appearance of $\mathrm{V}$ signal. It is worth noting that the location of 
$\mathrm{V}$ closely follows zinc distribution (Fig. 3c). The highest concentration of zinc and vanadium is observed in the areas containing LDH flakes and suggests the loading of vanadate into the LDH structure.

In order to confirm the $\mathrm{LDH}$ structure of these flakes and to prove intercalation of inhibiting anions between the layers, the grazing angle XRD was used. The XRD patterns of the PEO sample, coatings with $\mathrm{LDH}-\mathrm{NO}_{3}$ and $\mathrm{LDH}-\mathrm{VO}_{\mathrm{x}}$ sealing are shown in Fig. 4. No XRD lines were observed in the 2 theta range between $5^{\circ}$ and $35^{\circ}$ in the case of PEO coated AA2024. There is only a broad peak in the range of $17-35^{\circ}$ which can be associated to presence of $\mathrm{Al}_{2} \mathrm{O}_{3}$ in amorphous or nano-crystalline form. In contrast, the diffractogram of PEO-LDH-NO 3 shows well-defined peaks at $9.71^{\circ}$ and $19.66^{\circ}$ which can be assigned to (003) and (006) reflections of LDH $\left[{ }^{40}\right]$. These reflections correspond to a basal spacing of $9.13 \AA$ given that the total thickness of $\mathrm{Zn} / \mathrm{Al}$ hydroxide layer is about $\left.4.77 \AA{ }^{38}\right]$, the interlayer space available for $\mathrm{NO}_{3}{ }^{-}$corresponds to $4.36 \AA$.

The anion-exchange reaction between nitrate and vanadate anions leads to a remarkable shift of the peak positions in the XRD pattern (Fig. 4). The gallery height increases from $4.36 \AA(\mathrm{d}(003)$ $=9.13 \AA)$ to $4.84 \AA(\mathrm{d}(003)=9.61 \AA)$. No reflections corresponding to the $\mathrm{LDH}^{-\mathrm{NO}_{3}}$ were detected after the incorporation, indicating complete exchange of nitrate by vanadate. Immersion of $\mathrm{LDH}-\mathrm{VO}_{\mathrm{x}}$ in chloride containing electrolyte (1 week) leads to another important shift of diffraction peaks demonstrating possibility of further substitution of vanadate anions by chlorides from the solution. Thus the XRD results suggest that the flakes formed on PEO coatings most likely have LDH structure with exchangeable interlayer anions.

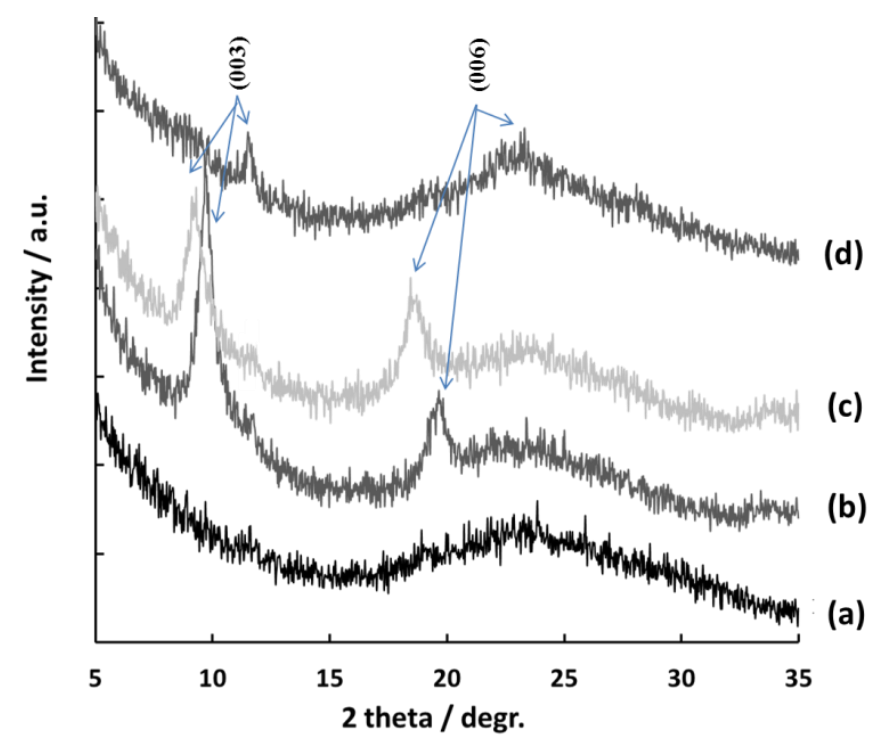

Fig. 4. X-ray diffraction patterns of the PEO sample (a), $\mathrm{PEO}$ sample with $\mathrm{LDH}-\mathrm{NO}_{3}(\mathrm{~b}), \mathrm{PEO}$ sample with $\mathrm{LDH}-\mathrm{VO} \mathrm{x}_{(}(\mathrm{c})$ and PEO sample with $\mathrm{LDH}-\mathrm{Cl}(\mathrm{d})$

In order to validate this assumption, the electron diffraction measurements using TEM were additionally performed. The TEM micrographs of PEO coated AA2024, PEO sample with LDH$\mathrm{NO}_{3}$ and PEO sample with $\mathrm{LDH}-\mathrm{VO}_{x}$ are illustrated in Fig. 5. 
TEM study of the substrate/coating interface of the AA2024 alloy after PEO treatment reveals the presence of an inner barrier layer of $\sim 200 \mathrm{~nm}$-thick with nanopores, probably related to the trapped gases evolved during the process (Fig. 5a) $\left[{ }^{41},{ }^{42}\right]$. In the outer film region, the observed cavity (connecting the substrate to the coating surface) is associated with the discharge channel formed during the PEO process. Molten alumina erupts through these channels, spills around the crater and rapidly solidifies, leaving a gas-filled void inside the and homogeneous dense material around the mouth of the crater as seen in Fig. 5a; hence this process facilitates transport of new coating material outwards. However, due to differences in cooling rates and temperatures of the individual microdischarges, the microstructure of the coatings is characterized by locally variable surface porosity in terms of shape and size of the pores $\left[{ }^{43}\right]$.

The PEO-coated AA2024 contains an amorphous PEO layer as indicated by the amorphous ring of the PEO diffraction pattern (Fig. 5a). Well defined LDH flakes can be observed in the case of sample treated with $\mathrm{LDH}_{-} \mathrm{NO}_{3}$ (Fig. 5b). These flakes were detected both on the surface of the PEO layer and within the pores suggesting certain possibility of sealing. The diffraction pattern obtained on such particles shows both the ring like structure and the additional reflections from the larger flakes. The rings correspond to $d$-spacing equal to $9.13 \AA$. The ring diameter tends to change after the anion exchange with vanadate (Fig. 5c) resulting in the increased $d$-spacing. Thus the TEM results additionally prove that the conversion treatment in the zinc nitrate containing bath forms LDH structures throughout the layer. Moreover the ion-exchange process allows incorporation of vanadate between the $\mathrm{LDH}$ layers and results in formation of nanocontainers with corrosion inhibitor.

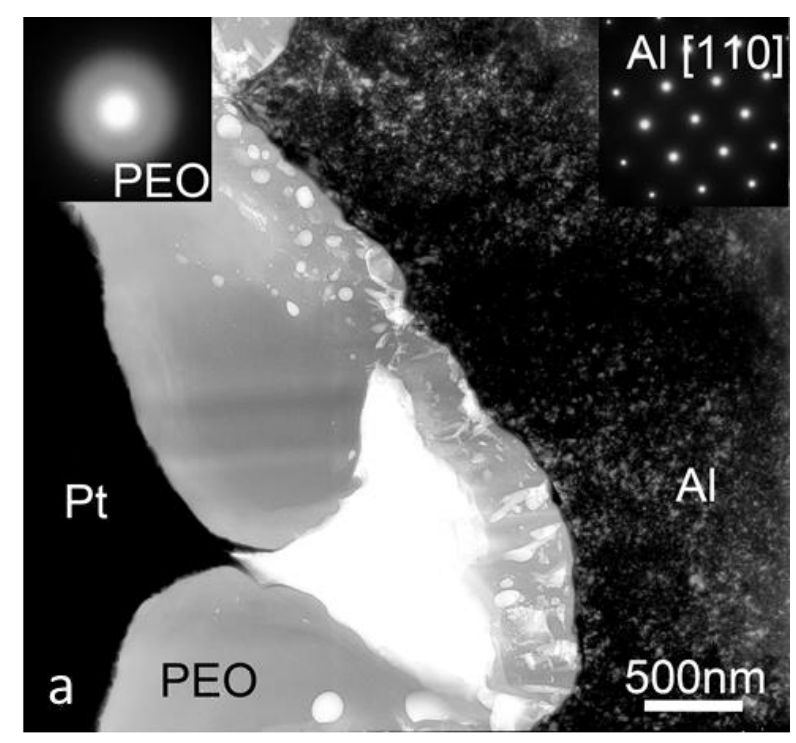



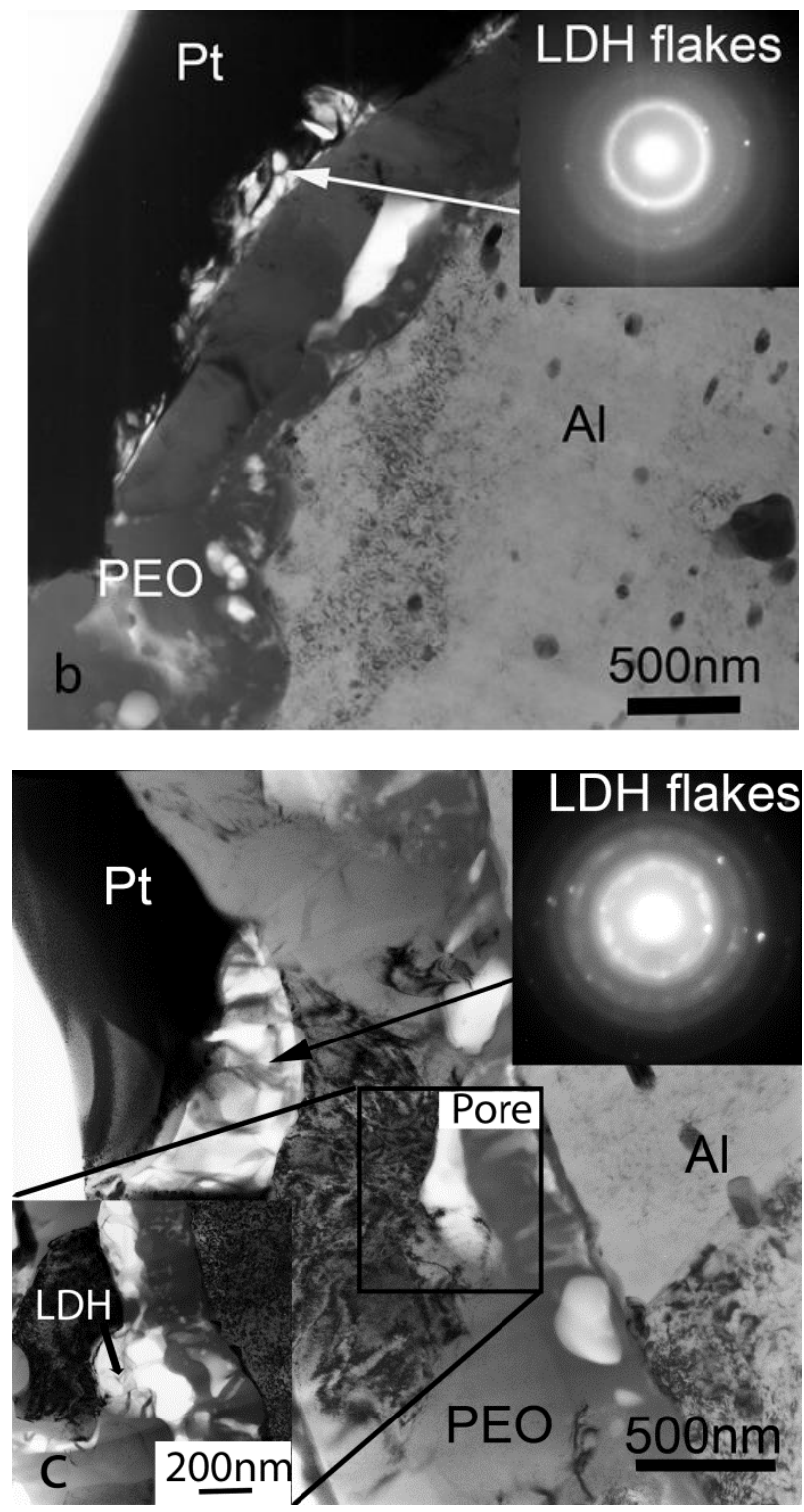

Fig. 5. TEM micrographs and associated diffraction patterns showing PEO sample (a), PEO sample with LDH$\mathrm{NO}_{3}(\mathrm{~b})$ and $\mathrm{PEO}$ sample with $\mathrm{LDH}-\mathrm{VO}_{x}(\mathrm{c})$.

The depth profile analysis for the main elements across the coating was performed using GDOES in order to estimate penetration of LDH into the pores of PEO layer (Fig. 6). 


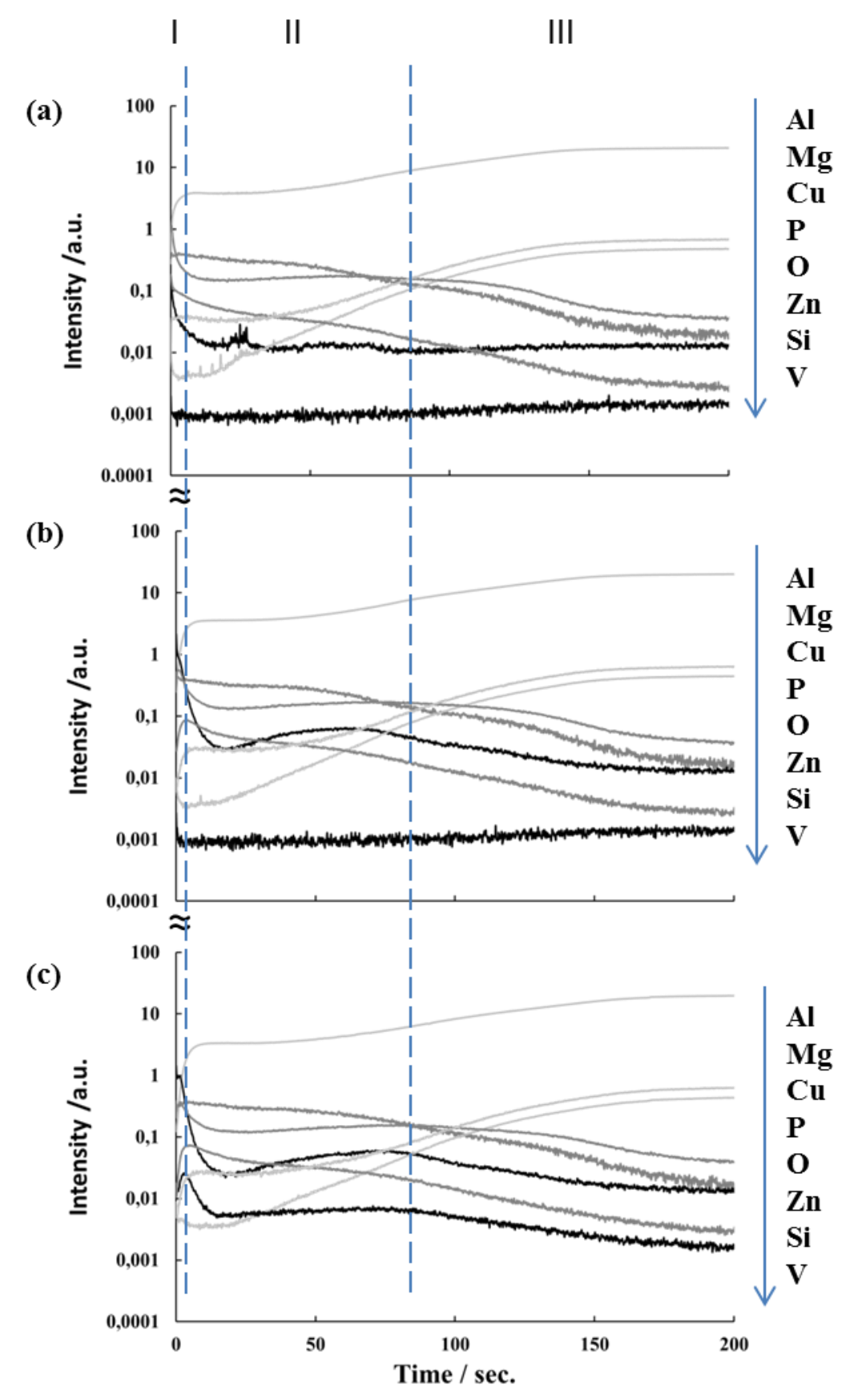

Fig. 6. GDOES depth profile of PEO sample (a), PEO sample with $\mathrm{LDH}-\mathrm{NO}_{3}$ (b) and PEO sample with $\mathrm{LDH}$ $\boldsymbol{V O} \boldsymbol{O}_{x}(c)$.

The PEO coating demonstrates a typical distribution of elements with increase of the main elements present in the alloy while approaching the surface. In contrast, silicon, phosphorus and oxygen are found in the PEO layer and their signals decrease down to noise levels during sputtering of the alloy. Very low detected zinc signal is due to the sputtering of alloying impurities from the AA2024. No vanadium was detected in the blank PEO sample. In the case of PEO-LDH-NO${ }_{3}$ sample an additional higher zinc signal can be observed at the beginning of sputtering (Fig. 6b, zone I), due to the formation of $\mathrm{Zn}-\mathrm{Al}-\mathrm{NO}_{3} \mathrm{LDH}$ on the surface which is sputtered before the PEO layer. During sputtering of the PEO layer (zone II) and the beginning of AA2024 alloy sputtering, the zinc signal decreases (due to the lower amount of LDH in pores 
than on the surface) and after that increases again next to the substrate interface. It can be concluded that growth of LDH preferably occurs at two different locations namely the top surface of the PEO layer and the bottom of the porous layer in proximity to the alloy surface. During the alloy sputtering (zone III) the signal of zinc becomes negligible. Two different growth mechanisms can be suggested in this case being relate to dissolution of $\mathrm{Al}$ oxides/hydroxides from the PEO layer and the dissolution of aluminum close to the interface as main sources of trivalent metal cations for $\mathrm{LDH}$ formation. It should be mentioned, that aluminum alloys are always covered by a natural oxide layer $\left[{ }^{44}\right]$ and the dissolution of aluminum from the substrate should be considered as dissolution of natural oxide film.

After ion-exchange is performed an important increase of $\mathrm{V}$ element can be evidenced. Importantly the distribution of $\mathrm{V}$ closely follows distribution of $\mathrm{Zn}$ suggesting that the ionexchange occurs not only in the LDH layer formed at top surface but also takes place in the pores near to the metal/oxide interface. Such a profile also confirms that presence of $\mathrm{V}$ is associated to LDH flakes rather than to simple adsorption of vanadate on the walls of pores.

The combination of the XRD, SEM, TEM, EDX, and GDOES results bring all the evidences that the suggested hydrothermal treatment leads to formation of $\mathrm{Zn}-\mathrm{Al} \mathrm{LDH}$ in the pores of PEO coating as a result of conversion process. The LDH growth depends strongly on the dissolution of amorphous and $\mathrm{\gamma}-\mathrm{Al}_{2} \mathrm{O}_{3}$ (in the presence of hydroxides) from the PEO coating or from AA2024 substrate through the pores (dissolution of amorphous natural oxide from the AA2024 surface). Generally $\mathrm{Zn}-\mathrm{Al}$ LDH synthesis could be explained via following chemical reactions $\left[{ }^{45}\right]$ :

$$
\begin{aligned}
& \mathrm{Al}_{2} \mathrm{O}_{3}+3 \mathrm{H}_{2} \mathrm{O}+2 \mathrm{OH}^{-} \rightarrow 2 \mathrm{Al}(\mathrm{OH})_{4}^{-} \\
& \mathrm{Zn}^{2+}+\mathrm{OH}^{-} \rightarrow \mathrm{Zn}(\mathrm{OH})^{+} \\
& \mathrm{Zn}(\mathrm{OH})^{+}+\mathrm{Al}(\mathrm{OH})_{4}^{-}+\mathrm{NO}_{3}{ }^{-}+\mathrm{H}_{2} \mathrm{O} \rightarrow \mathrm{LDH}_{-} \mathrm{NO}_{3}
\end{aligned}
$$

The ion-exchange step allows incorporating vanadate ions within the LDH gallery and creates nanocontainers of corrosion inhibitors directly inside the PEO layer and most importantly next to the interface with metal.

\section{Corrosion protection and self-healing properties of PEO/LDH systems}

A combination of integral and localized electrochemical techniques was employed to evaluate the effect of LDH sealing on the corrosion protection performance of the PEO coatings and to confirm its improved fault tolerance. 
Fig. 7 shows Bode plots for the parental PEO coated alloy (Fig. 7a, b), PEO with $\mathrm{LDH}^{-\mathrm{NO}_{3}}$ (Fig. 7c,d) and PEO with $\mathrm{LDH}^{-\mathrm{VO}_{\mathrm{x}}}(\mathbf{F i g}$. 7e, $\mathbf{f})$ after different time of immersion in 0.5 wt.\% $\mathrm{NaCl}$ solution.
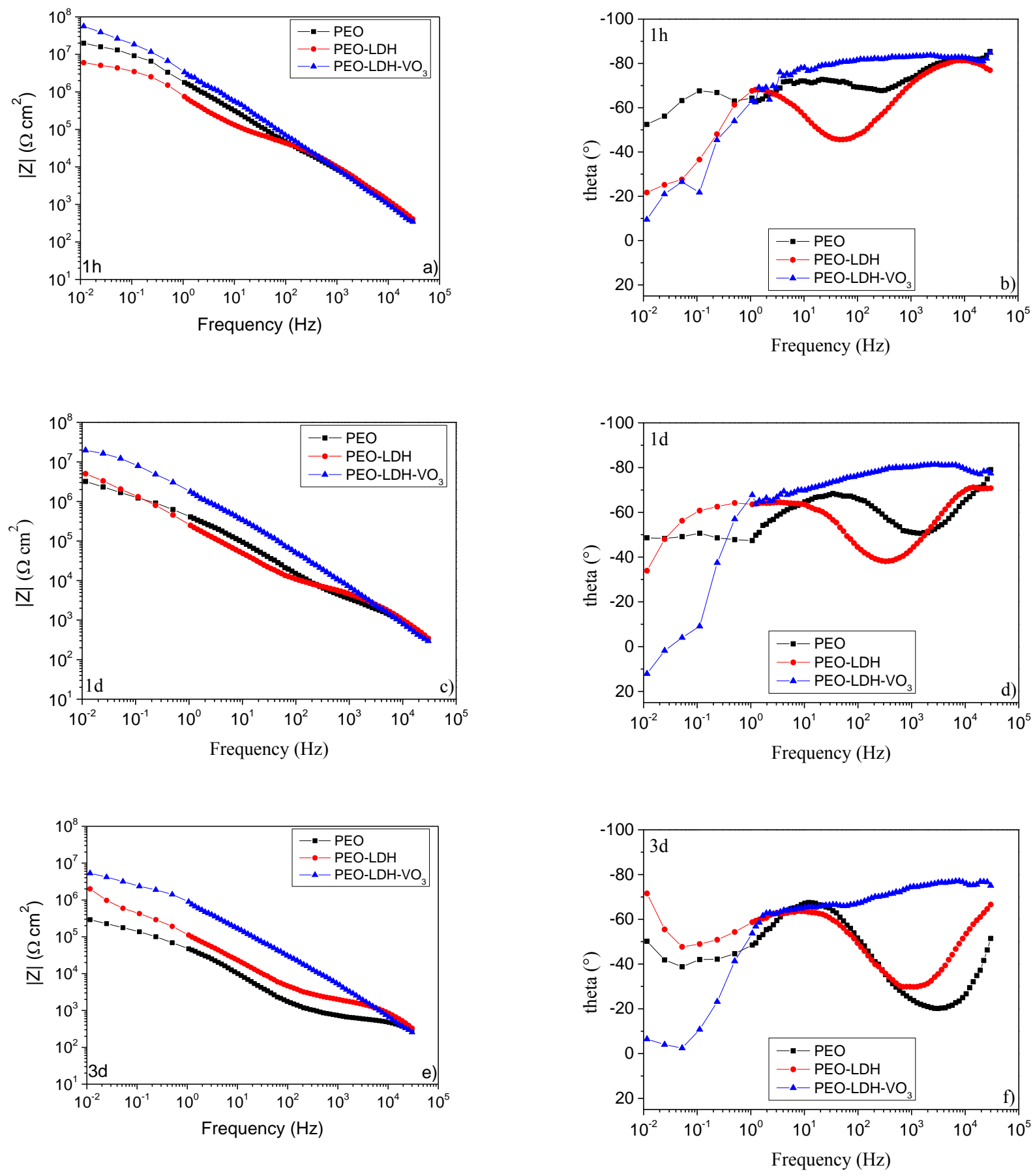

Fig 7. Bode plots for PEO sample, $\mathrm{PEO}$ sample with $\mathrm{LDH}-\mathrm{NO}_{3}$ and $\mathrm{PEO}$ sample with $\mathrm{LDH}-\mathrm{VO}$ a after different times of immersion in $0.5 \mathrm{wt}$.\% $\mathrm{NaCl}$ solution $(a, b) 1 \mathrm{~h}(c, d) 1 d(e, f) 3 d$.

The impedance response for the coated substrates indicates presence of several relaxation processes. The time constants not always can be easily separated due to a strong overlaping especially in the case of PEO-LDH- $\mathrm{VO}_{\mathrm{x}}$ system. 
The relaxation process observed at high-frequency $\left(10^{3} \mathrm{~Hz}\right)$ is ascribed to the response of the porous part of the coating, whereas the middle frequency response of the system $\left(10^{1}-10^{2} \mathrm{~Hz}\right)$ can be attributed to the inner barrier layer of the PEO coating. These two components are hard to separate especially in the beginning of immersion. The response of the electrochemical activities on the alloy surface can be attributed to the low-frequency time constant $(0.1 \mathrm{~Hz})$.

The higher impedance modulus at low frequencies $(0.01 \mathrm{~Hz})$ reveals the beneficial effect of $\mathrm{LDH}-\mathrm{VO}_{\mathrm{x}}$ on the corrosion resistance of PEO coatings for all immersion times. For short times of immersion (up to $1 \mathrm{~h}$ ) high values of the impedance modulus $\left(10^{6}-10^{7} \Omega \cdot \mathrm{cm}^{2}\right.$ ) at low frequencies are obtained for all the samples due to the good protective character of the PEO layers at this stage. The lowest value obtained for PEO-LDH can be associated with a loss of the protective barrier properties of the coating during the formation of LDH under conditions described in 2.2. However, after 1 day of immersion PEO coating with LDH treatment maintains the value of low frequency impedance while the blank PEO system demonstrates a significant drop. This effect can be related to the trapping of $\mathrm{Cl}^{-}$ions in the pores close to metal/oxide interface by the LDH structure and preventing fast development of chloride-induced corrosion processes $\left[{ }^{46}\right]$.

After longer immersion, all the coatings show the typical behavior for this type of layers with a continuous decrease of low-frequency impedance modulus over up to 2 orders of magnitude. However, PEO-LDH- $\mathrm{VO}_{\mathrm{x}}$ showed the highest values of total impedance for all times of immersion with values up to 1 order of magnitude higher compared to PEO and PEO-LDH. This improvement after $\mathrm{LDH}-\mathrm{VO}_{\mathrm{x}}$ post-treatment might be associated with different factors: i) additional sealing effect: large-sized pores (Fig. 2) were partially filled with LDH flakes delaying the permeation of the electrolyte into the inner layer, ii) incorporation of inhibitor species: suppression of corrosion activity via release of vanadate when chloride penetrates.

The equivalent circuit used to fit the electrical parameters is shown in Fig. 8 along with an example of the fitting of the experimental data. For the equivalent circuit, the $\mathrm{R}_{\mathrm{S}}$ corresponds to the solution resistance, $\mathrm{CPE}_{\text {por }}$ and $\mathrm{R}_{\text {por }}$ are associated with the capacitive and resistive response of the porous part of the coating (through-going discharge channels, crack and pores), and $\mathrm{CPE}_{\mathrm{bar}}$ and $\mathrm{R}_{\mathrm{bar}}$ are ascribed to the capacitance and pore resistance of the dense inner barrier layer. The electrochemical activities can be described by the double layer capacitance of the electrolyte/metal interface $\left(\mathrm{CPE}_{\mathrm{dl}}\right)$ and charge transfer resistance across it $\left(R_{\mathrm{ct}}\right)$. Constant Phase Elements (CPE) were used rather than capacitances to account for non-ideal behavior of the system. 


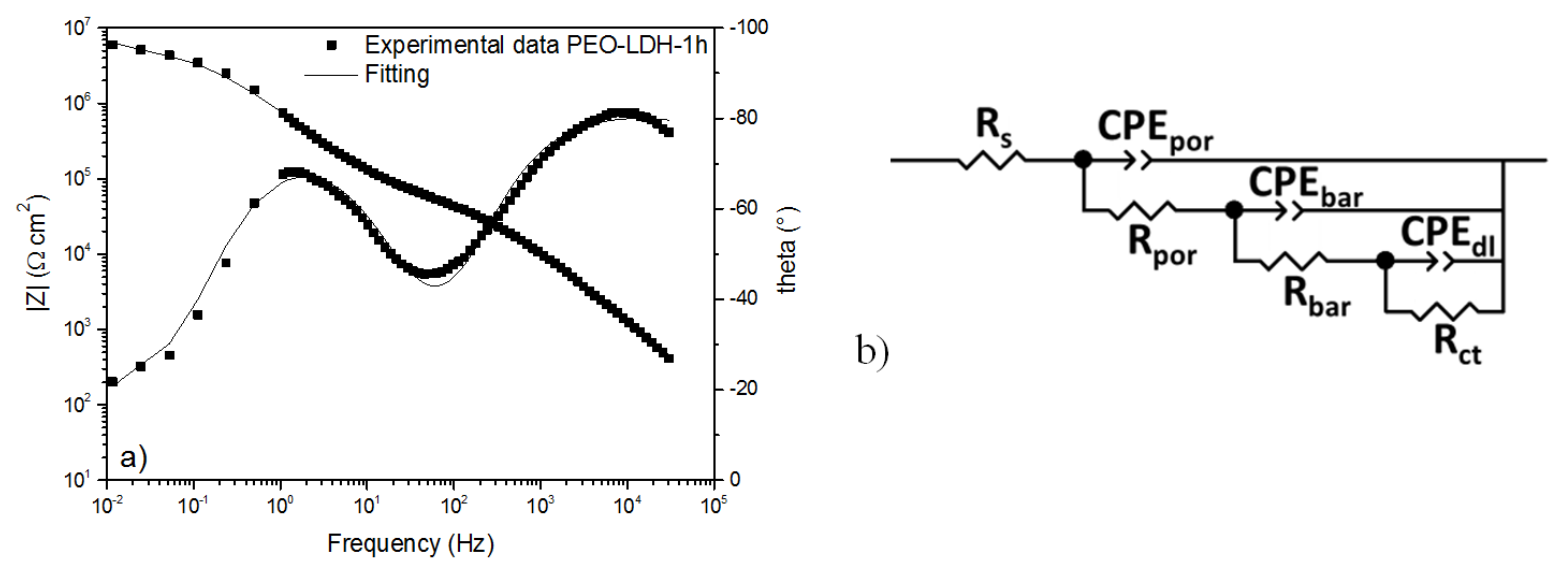

Fig. 8. a) An example of the fitting of experimental impedance spectrum and b) the equivalent circuit used to model the impedance data

In order to evaluate the degradation behavior of the PEO coatings and the influence of $\mathrm{LDH}-\mathrm{NO}_{3}$ and $\mathrm{LDH}-\mathrm{VO}_{\mathrm{x}}$ treatments, the evolution of the resistance corresponding to the porous part of the coating $\left(\mathrm{R}_{\text {por }}\right)$ and the resistance corresponding to barrier inner layer $\left(\mathrm{R}_{\mathrm{bar}}\right)$ has been plotted in Fig. 9.

The PEO-LDH- $\mathrm{VO}_{\mathrm{x}}$ coating shows the highest values of the pore resistance for all times of immersion (Fig. 9a). This is associated mainly with the better sealing of the pores after double post-treatments (LDH synthesis and anion-exchange) increasing the resistance of the pores which determines the total resistance of the outer part. PEO-LDH-NO 3 also shows a slight improvement of the outer part properties, particularly for shorter immersion times, as the LDH flakes cover the surface of the coating. For longer immersion times, there is a decrease in this resistance indicating that the electrolyte can penetrate through the porous regions and the chemical degradation of the coating occurs, leading to the loss of the barrier properties of the outer layer. In fact, after 1 day of immersion the contribution of this resistance is relatively low for PEO and PEO-LDH-NO (with values in the order of $10^{3} \mathrm{ohm} \mathrm{cm}^{2}$ ), as reported previously for this type of coatings $\left[{ }^{47}\right]$. However, PEO-LDH-VO $\mathrm{V}_{\mathrm{x}}$ revealed an improvement in the pore resistance of outer layer values up to $10^{5} \mathrm{ohm} \mathrm{cm}^{2}$. This can be related to the presence of vanadate, confirmed by EDX mapping and GDOES (Fig. 4). 

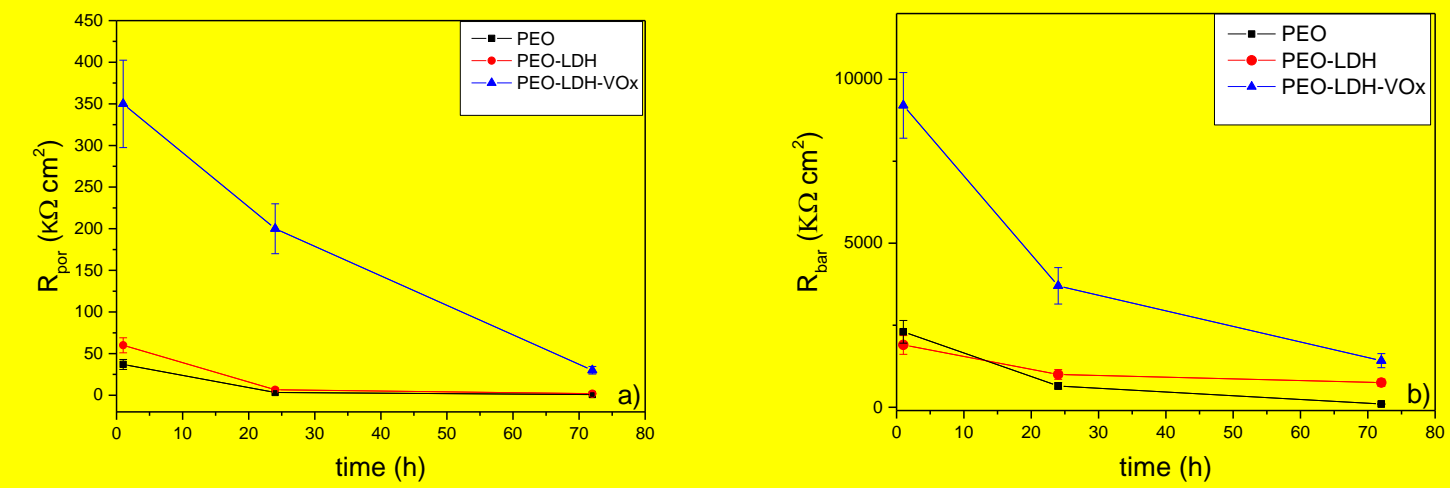

Fig. 9. Evolution of resistance for all the materials with the immersion time up to 3 days of immersion in 0.5 wt \% $\mathrm{NaCl}$ solution a) $\boldsymbol{R}_{\text {por }}$ b) $\boldsymbol{R}_{\text {bar }}$

The evolution of the resistance of the inner barrier layer (Fig. 9b) for the three systems reveals a decrease with time. For all immersion times, $\mathrm{PEO}-\mathrm{LDH}-\mathrm{VO}_{\mathrm{x}}$ shows the highest values indicating better corrosion properties after the post-treatments with inhibitors. $\mathrm{R}_{\text {bar }}$ results for shorter immersion times (up to $1 \mathrm{~h}$ ) show slightly lower values of PEO-LDH-NO ${ }_{3}$ compared to PEO coating. This might be related to the weakening of the inner barrier layer during the synthesis of $\mathrm{LDH}$ which can be explained by the dissolution of $\mathrm{Al}$ cations from the substrate and oxide barrier layer in order to form LDH.

The beneficial effect of post-sealing processes in terms of corrosion behavior, is well known for anodic layers (e.g boiling water, silicates, polymer solutions and sol-gel coatings $\left[{ }^{48,49,50}\right]$ ) but for PEO coatings on $\mathrm{Al}$ only few investigations are reported mostly based on sol-gel treatments $\left.{ }^{51}\right]$.

Regarding sealing methods based on aqueous solutions, in previous work it was found that the total impedance of the PEO coatings on Al increased after the application of post-treatments based on salts of nickel, cerium, potassium permanganate and phosphonic acid. However, these types of sealing do not confer coatings with an active protection $\left[{ }^{11}\right]$. In the present work, based only on EIS analysis, it is also not possible to confirm if there is a self-sealing effect due to the presence of inhibitors in the PEO coating or just a general improvement of corrosion protection originated from enhanced barrier properties.

The scanning vibrating electrode technique (SVET) was additionally used in order to prove the self-healing effect and validate the enhanced fault-tolerance of developed coatings. SVET allows monitoring of evolution of the anodic and cathodic corrosion current densities in artificial microscale defects. Fig. 10 presents the microphotographs after 22 hours of immersion and SVET maps taken in $0.05 \mathrm{M} \mathrm{NaCl}$ after 2h, $10 \mathrm{~h}$, and 24 hours for the PEO coated AA2024 sample (a), PEO-LDH-NO $\mathrm{N}_{3}$ (b) and for PEO-LDH-VO $\mathrm{V}_{\mathrm{x}}$ (c). All samples contain two artificially drilled 
defects $(100 \mu \mathrm{m}$ diameter and $20 \mu \mathrm{m}$ depth in order to reach the aluminum substrate) with a distance of $1 \mathrm{~mm}$ between them. The fact that PEO coating was removed and bare substrate is reached in the zone of defects was controlled via an electrical conductivity check.

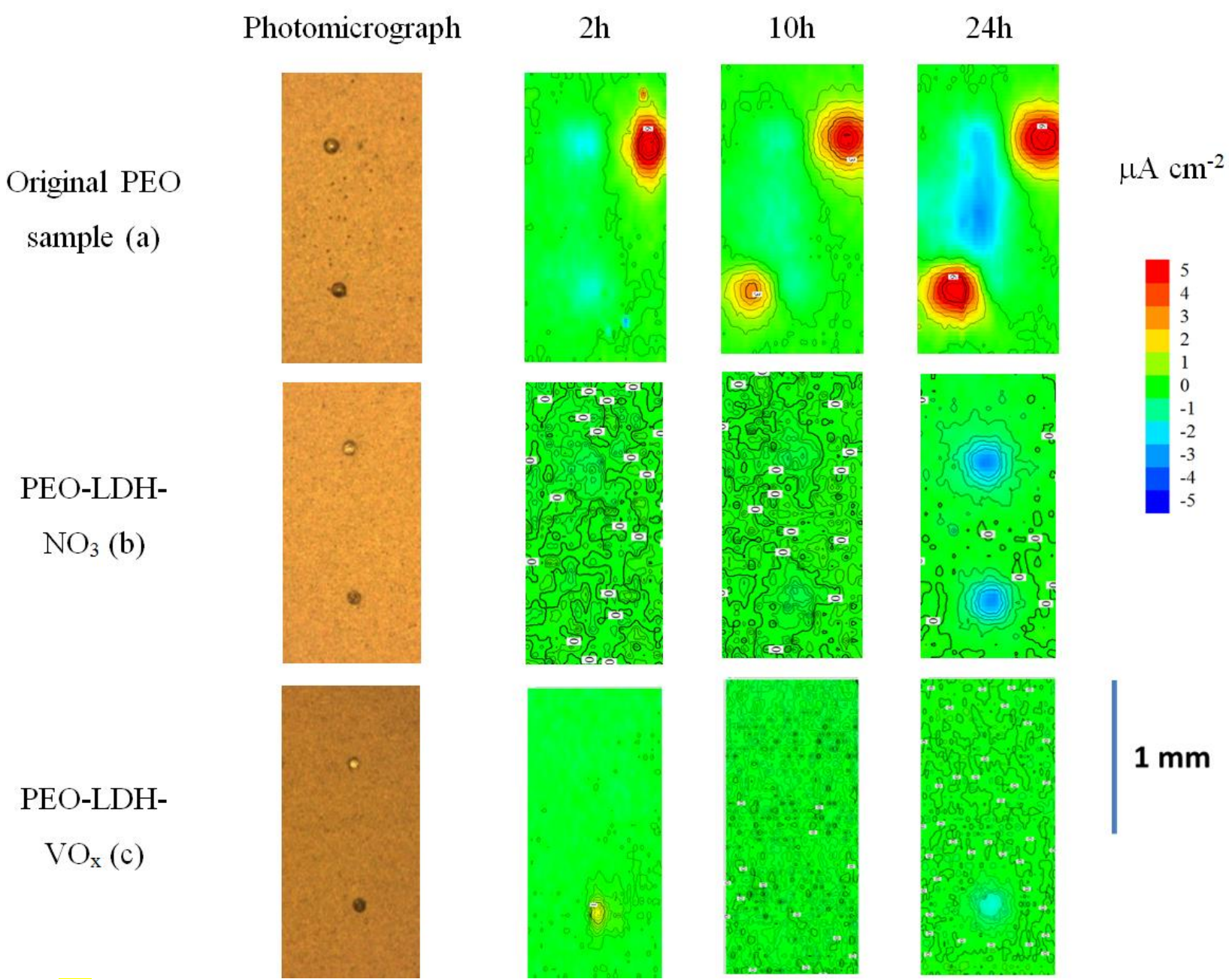

Fig.10. Micrographs and SVET maps of PEO sample (a), PEO sample with $\mathrm{LDH}-\mathrm{NO}_{3}(\mathrm{~b})$ and $\mathrm{PEO}$ sample with $\mathrm{LDH}-\mathrm{VO} \mathrm{x}_{(\mathrm{c})}$ after $2 \mathrm{~h}, 10 \mathrm{~h}$ and $24 \mathrm{~h}$ of immersion in $0.05 \mathrm{M} \mathrm{NaCl}$

Well defined corrosion activities are visible in the case of PEO coated AA2024. The corrosion starts not only at the artificial defects but also in other locations (can be seen in right top corner and left bottom corner in Fig. 10a at 24 hours measurement) confirming the need for a sealing post-treatment.

A significant delay in corrosion activities in the defect zone is observed for the sample with $\mathrm{LDH}-\mathrm{NO}_{3}$. The corrosion currents are detected in the defects only after $24 \mathrm{~h}$ of immersion. The rest of the surface still stay inactive in contrast to the unsealed PEO system. This improved behavior agrees well with the EIS results presented above and can be associated either to the active entrapment of aggressive chlorides or to the total improvement of barrier properties due to the pores sealing of PEO layer.

The best corrosion protection performance was observed when the corrosion inhibitor is loaded into LDH nanocontainers. The fault tolerance of this system is drastically increased. After $24 \mathrm{~h}$ 
only minor signs of electrochemical activity are visible at the artificial defects. These results provide a clear evidence of self-healing properties conferred by $\mathrm{LDH}^{-\mathrm{VO}_{\mathrm{x}}}$ sealing treatment rather than just improvement of the barrier layer due to the sealing. The cathodic currents detected in both artificial (see photomicrographs in Fig. 10) defects of the same sample can be related to the fact that cathodic processes are controlled by the diffusion of oxygen. Local removal of the coating accelerates the oxygen transport in defects making them predominantly cathodic while the anodic activity is distributed over the larger area under the coating.

In order to illustrate that the self-healing action is indeed related to the release of corrosion inhibitor on demand via ion-exchange mechanism additional XRD studies were performed as briefly mentioned above. The PEO-LDH-VO $\mathrm{VO}_{\mathrm{x}}$ specimen was analyzed after 1 week of immersion in 0.5 wt. \% $\mathrm{NaCl}$ solution at room temperature. The XRD pattern from the resulting $\mathrm{LDH}$ is presented in Fig. 3 labeled $\mathrm{PEO}-\mathrm{LDH}-\mathrm{Cl}$. The (003) peak of $\mathrm{LDH}$ is shifted to $11.43^{\circ}$, which correspond to a gallery height equal to $7.68 \AA$. These results are in a good agreement with the reported structural data for $\mathrm{LDH}-\mathrm{Cl}\left[{ }^{52},{ }^{53}\right]$ and confirm that $\mathrm{LDH}$ may play an important role in "smart" anti-corrosion protection by: (1) the release of anti-corrosion inhibitor (vanadate) on demand in the presence of aggressive $\mathrm{Cl}^{-}$in the environment and (2) the adsorption of $\mathrm{Cl}^{-}$into the $\mathrm{LDH}$ layer (valid both for $\mathrm{LDH}-\mathrm{NO}_{3}$ and $\mathrm{LDH}-\mathrm{VO}_{\mathrm{x}}$ specimens).

Altogether, the XRD results support the role of LDH in the active corrosion protection concept by ion-exchange processes on demand and the SVET results have demonstrated the positive influence of $\mathrm{LDH}-\mathrm{VO}_{\mathrm{x}}$ on the corrosion processes.

In summary, the possible mechanism of "smart" self-healing protection of LDH-sealed PEO coatings is schematized in Fig. 11. The corrosive degradation of PEO coated substrate is accelerated by effect of chloride ions present in the environment $\left[{ }^{54}\right]$. Partial entrapment of chloride anions via ion-exchange mechanism is possible when PEO layer is sealed with LDH (Fig. 11a). However, the inhibition effect provided by nitrate anions is significantly lower than can be expected in the case of vanadate $\left[{ }^{55}\right]$. Therefore the corrosion activity starts to accelerate with time as seen on respective SVET maps. In contrast the vanadate anions released from the $\mathrm{LDH}$ in presence of chlorides can confer an additional inhibition in the defect (Fig. 11b) ensuring long-term active protection.

It was previously shown by Salak et al $\left[{ }^{56}\right]$ that under the similar conditions LDH is loaded with pyrovanadate $\left(\mathrm{V}_{2}\right)$. These species are suitable for inhibition of aluminum corrosion $\left[{ }^{55},{ }^{57}\right]$ via suppression of oxygen reduction kinetics (schematically indicated in Fig. 11(b)) and suppression of intermetallic phase dissolution reducing their cathodic activity. Supposedly, in the opened 
pores or in the artificial defects the vanadate species act in the same way as on bare surface in terms of inhibition mechanism $\left(\mathrm{V}_{1}-\mathrm{V}_{3}\right.$ provide an effective inhibition for the aluminum alloy in accordance with previously published $\left.\left[{ }^{55}\right]\right)$.
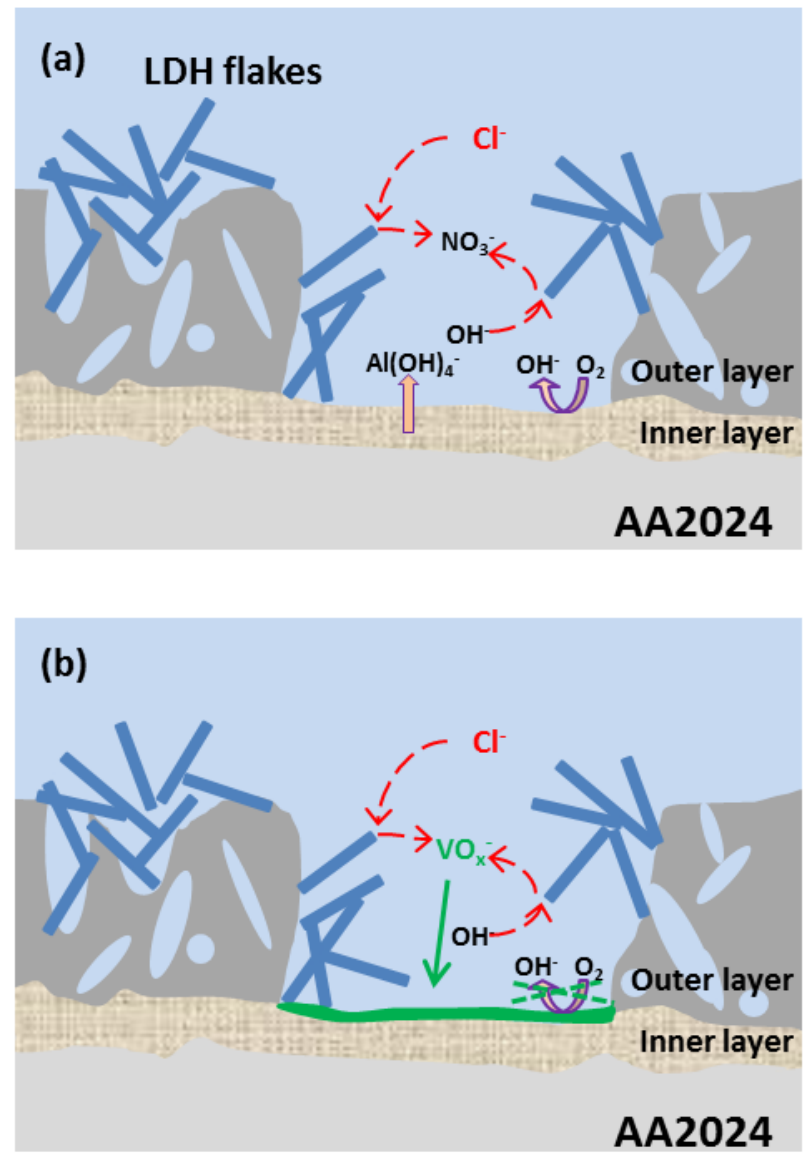

Fig.11. The possible mechanism of active corrosion protection (a) $\mathrm{PEO}$ sample with $\mathrm{LDH}-\mathrm{NO}_{3}$ and (b) $\mathrm{PEO}$ sample with $\mathrm{LDH}-\mathrm{VO} \mathrm{O}_{x}$

However, in spite of promising results showing the effective combination of barrier properties, provided by PEO, and active protection, provided by LDH loaded with inhibitor, authors would like to underline the novelty of the system and possibility to improve it more in frame of further works. The first improvement can be addressed to the search of more environmentally friendly inhibitor, rather than vanadate, used in this work. Different organic and inorganic inhibitors can be considered, as soon as they would fulfill the requirement of effective corrosion protection, charge/size ratio and environmental regulations. The chemical composition (like different cations and their ratio) of LDH hydroxide layers can be also a matter of further work. It was recently shown, that LiAl LDHs can be already formed under the conditions, close to the room temperature $\left[{ }^{58}\right]$. They also can be loaded with corrosion inhibitors and used for active corrosion protection. Moreover, Li-based corrosion products can provide the inhibitive properties for 
aluminum alloys when LDH is already used. All this facts will let us further improve the PEObased protection system for aluminum alloys.

\section{Conclusions}

A new method of active anti-corrosion sealing for PEO coatings on aluminum based substrates is reported in this work. The sealing is based on the in-situ formation of LDH-nanocontainers of corrosion inhibitor using sequence of hydrothermal conversion process followed by the ionexchange reaction.

The hydrothermal treatment in Zn-containing bath causes the LDH structures to form on top and in the pores of the PEO layer. When loaded with corrosion inhibiting anions (vanadate in this case), LDH functions as "smart" active nanocontainers. The results show that such a sealing improves the corrosion performance and effectively heal the defects suppressing corrosion.

The LDH-based post-treatment is a promising potential candidate for $\mathrm{Cr}$-free sealing of the PEO treated AA2024 alloy. Moreover it can be overpainted in order to ensure superior barrier properties still keeping the enhanced fault tolerance.

\section{Acknowledgements}

This work in part was financed by the European project MULTISURF (Marie Skłodowska-Curie grant agreement No 645676). MM acknowledges the Alexander von Humboldt Foundation, Germany, for the award of AvH research fellowship and financial assistance. The technical support of Mr. U. Burmester and Mr. V. Heitmann is gratefully acknowledged. Authors are grateful to Prof. Florian Pyczak and Mr. Uwe Lorenz for providing access to the TEM facilities at Helmholtz-Zentrum Geesthacht. This work was partially conducted within the framework of the project CICECO-Aveiro Institute of Materials, POCI-01-0145-FEDER-007679 (FCT Ref. UID /CTM /50011/2013), financed by national funds through the FCT/MEC and co-financed by FEDER (PT2020 Partnership Agreement).

\section{References}

\footnotetext{
${ }^{1}$ A.L. Yerokhin, X. Nie, A. Leyland, A. Matthews, S.J. Dowey, "Plasma electrolysis for surface engineering", Surf. Coat. Technol., 122 (1999), pp. 73-93

${ }^{2}$ A. Curran, T.W. Clyne, Thermo-physical properties of plasma electrolytic oxide coatings on aluminium, Coat. Technol., 199 (2005), 168-179

${ }^{3}$ M. Mohedano, E. Matykina, R. Arrabal, A. Pardo, M.C. Merino, "Metal release from ceramic coatings for dental implants" Dental Materials, 30 (3) (2014) e28-e40
} 
${ }^{4}$ J A Curran, H Kalkanc, Y Magurova, T W Clyne, "Mullite-rich plasma electrolytic oxide coatings for thermal barrier applications', Surf Coat Technol, 201 (2007) 8683-8687.

${ }^{5}$ Y. Goueffon, L. Arurault, C. Mabruc, C. Tonond, P. Guiguea, "Black anodic coatings for space applications, Study of the process parameters, characteristics and mechanical properties", Journal of Materials Processing Technology 209 (2009) 5145-5151.

${ }^{6}$ E. Matykina, R. Arrabal, P. Skeldon, G.E. Thompson, "Investigation of the growth processes of coatings formed by AC plasma electrolytic oxidation of aluminium", Surf. Coat. Technol., 54 (2009) 6767-6778

${ }^{7}$ P. Mertsalo, V.T. Yavors'kyi, M.D. Klapkiv, R.S. Mardarevych, "Wear Resistance of Anodic-Spark Coatings on Aluminum Alloys" Mater. Sci., 39 (2003) 136-139

${ }^{8}$ X. Lu, C. Blawert, M. Mohedano, N. Scharnagl, M.L. Zheludkevich, K.U. Kainer, "Influence of electrical parameters on particle uptake during plasma electrolytic oxidation processing of AM50 Mg alloy", Surface and Coatings Technology, 289 (2016) 179-185

${ }^{9}$ R. Arrabal, M. Mohedano, E. Matykina, A. Pardo, B. Mingo, M.C. Merino, "Characterization and wear behaviour of PEO coatings on 6082-T6 aluminium alloy with incorporated $\alpha$-A12O3 particles" Surface and Coatings Technology, 269 (2015) 64-73

${ }^{10}$ Z. Wang, L. Wu, Y. Qi, W. Cai, Z. Jiang, "Self-lubricating Al2O3/PTFE composite coating formation on surface of aluminium alloy" Surf. Coat. Technol., 204 (2010) 3315-3318

${ }^{11}$ M. Mohedano, E. Matykina, R. Arrabal, B. Mingo, A. Pardo "PEO of pre-anodized Al-Si alloys: Corrosion properties and influence of sealings", Applied Surface Science, 346 (2015) 57-67

${ }^{12}$ R. Arrabal, J.M. Mota, A. Criado, A. Pardo, M. Mohedano, E. Matykina, "Assessment of duplex coating combining plasma electrolytic oxidation and polymer layer on AZ31 magnesium alloy", Surface and Coatings Technology, 206 (22) (2012) 4692-4703

${ }^{13}$ X. Nie, A. Wilson, A. Leyland, A. Matthews, "Deposition of duplex Al2O3/DLC coatings on Al alloys for tribological applications using a combined micro-arc oxidation and plasma-immersion ion implantation technique" Surf. Coat. Technol., 131 (2000) 506-513

${ }^{14}$ M. Mohedano, C. Blawert, M.L. Zheludkevich, "Cerium-based sealing of PEO coated AM50 magnesium alloy", Surface and Coatings Technology, 269 (2015) 145-154

${ }^{15}$ A.S. Gnedenkov, S.L. Sinebryukhov, D.V. Mashtalyar, S.V. Gnedenkov, Localized corrosion of the Mg alloys with inhibitor-containing coatings: SVET and SIET studies Corrosion Science, Volume 102, January 2016, Pages 269-278

${ }^{16}$ J. Tedim, M. L. Zheludkevich, A. N. Salak, A. Lisenkov and M. G. S. Ferreira, "Nanostructured LDH-container layer with active protection functionality" J. Mater. Chem., 21 (2011) 15464-15470

${ }^{17}$ Yi Wang, Dun Zhang, Zhou Lu "Hydrophobic Mg-Al layered double hydroxide film on aluminum: Fabrication and microbiologically influenced corrosion resistance properties", Colloids and Surfaces A: Physicochemical and Engineering Aspects 474 (2015) 44-51

${ }^{18}$ M. Zhou, X. Pang, L. Wei, K. Gao, "In-situ grown superhydrophobic Zn-Al layered double hydroxides films on magnesium alloy to improve corrosion properties", Applied Surface Science, 337 (2015) 172-177

${ }^{19}$ D. Scarpellini, C. Falconi, P. Gaudio, A. Mattoccia, P.G. Medaglia, A. Orsini, R. Pizzoferrato, M. Richetta, "Morphology of Zn/Al layered double hydroxide nanosheets grown onto aluminum thin films", Microelectronic Engineering 126 (2014) 129-133

${ }^{20}$ M.Serdechnova; S. Kallip, M.G.S. Ferreira, M.L. Zheludkevich, "Active Self-Healing Coating for Galvanically Coupled Multi-Material Assemblies”. Electrochem. Comm. 41 (2014) 51-54

${ }^{21}$ R. G. Buchheit, H. Guan, S. Mahajanam and F. Wong, "Active corrosion protection and corrosion sensing in chromate-free organic coatings" Prog. Org. Coat., 47 (2003) 174-182.

${ }^{22}$ M.L. Zheludkevich, S.K. Poznyak, L.M. Rodrigues, D. Raps, T. Hack, L.F. Dick, M.G.S. Ferreira, “Active protection coatings with layered double hydroxide nanocontainers of corrosion inhibitor" Corrosion Science, 52 (2010) 602-611.

${ }^{23}$ G. Williams, H.N. McMurray, "Anion-exchange inhibition of filiform corrosion on organic coated AA2024-T3 aluminum alloy by hydrotalcite-like pigments", Electrochem. Solid-State Lett. 6 (2003) B9-B11.

${ }^{24}$ K. Ogle, M. Serdechnova, M. Mokaddem, P. Volovitch "The cathodic dissolution of Al, $\mathrm{Al} 2 \mathrm{Cu}$, and $\mathrm{Al}$ alloys", Electrochimica Acta, 56 (4) (2011) 1711-1718 
${ }^{25}$ M. Serdechnova, P. Volovitch, Fr. Brisset, K. Ogle "On the cathodic dissolution of Al and Al alloys", Electrochimica Acta, 124 (2014) 9-16

${ }^{26}$ M. Serdechnova, A.N. Salak, F.S. Barbosa, D.E.L. Vieira, J. Tedim, M.L. Zheludkevich, M.G.S. Ferreira, "Interlayer intercalation and arrangement of 2-mercaptobenzothiazolate and 1,2,3-benzotriazolate anions in layered double hydroxides: in situ x-ray diffraction study", Journal of Solid State Chemistry, 233 (2016) 158-165

${ }^{27}$ Khan, A. I.; O'Hare, D. "Intercalation Chemistry of Layered Double Hydroxides: Recent Developments and Applications". J. Mater. Chem., 12 (2002) 3191-3198.

${ }^{28}$ Evans, D. E.; Slade, R. C. T. "Structural Aspects of Layered Double Hydroxides" in Structure \& Bonding; Springer-Verlag: Berlin, Germany, 119 (2005) 1-87

${ }^{29}$ M.L. Zheludkevich, J. Tedim, M.G.S. Ferreira “''Smart” coatings for active corrosion protection based on multifunctional micro and nanocontainers", Electrochimica Acta 82 (2012) 314-323

${ }^{30}$ A. Collazo, M. Hernández, X.R. Nóvoa, C. Pérez, "Effect of the addition of thermally activated hydrotalcite on the protective features of sol-gel coatings applied on AA2024 aluminium alloys" Electrochimica Acta 56 (23) (2011) 7805-7814

${ }^{31}$ To Thi Xuan Hang, Trinh Anh Truc, Nguyen Thuy Duong, Nadine Pébère, Marie-Georges Olivier, "Layered double hydroxides as containers of inhibitors in organic coatings for corrosion protection of carbon steel", Progress in Organic Coatings, 74 (2) (2012) 343-348

32 To Thi Xuan Hang, Trinh Anh Truc, Nguyen Thuy Duong, Pham Gia Vu, Thai Hoang, "Preparation and characterization of nanocontainers of corrosion inhibitor based on layered double hydroxides", Applied Clay Science, 67-68 (2012) 18-25

${ }^{33}$ B. Kuznetsov, M. Serdechnova, J. Tedim, M. Starykevich, S. Kallip, M.P. Oliveira, T. Hack, S. Nixon, M.G.S. Ferreira, M.L. Zheludkevich "Sealing of tartaric sulphuric (TSA) anodized AA2024 with nanostructured LDH layers" RSC Adv., 6 (2016) 13942-13952

${ }^{34}$ R. G. Buchheit, H. Guan, S. Mahajanam and F. Wong, "Active corrosion protection and corrosion sensing in chromate-free organic coatings" Progress in Organic Coatings, 47 (2003) 174

${ }^{35}$ A.L. Yerokhin, A. Shatrov, V. Samsonov, P. Shashkov, A. Pilkington, A. Leyland, A. Matthews "Oxide ceramic coatings on aluminium alloys produced by a pulsed bipolar plasma electrolytic oxidation process" Surface \& Coatings Technology 199 (2005) 150-157

${ }^{36}$ R.C. Barik, J.A. Wharton, R.J.K. Wood, K.R. Stokes, R.L. Jones "Corrosion, erosion and erosion-corrosion performance of plasma electrolytic oxidation (PEO) deposited A12O3 coatings" Surface \& Coatings Technology 199 (2005) 158- 167

${ }^{37}$ G. Szakács, C.L. Mendis, D. Tolnai, A. Stark, N. Schell, H. Ovri, M. Wolff, K.U. Kainer, J. Gröbner, R. SchmidFetzer, N. Hort "In Situ Synchrotron Radiation Diffraction during Solidification of Mg15Gd: Effect of Cooling Rate" TMS (The Minerals, Metals \& Materials Society ed. by M.V. Manuel, A. Singh, M. Alderman, N.R. Neelameggham), (2015) 79-84

${ }^{38}$ C. Liu, D. He, Q. Yan, Z. Huang, P. Liu, D. Li, G. Jiang, H. Ma, P. Nash, D. Shen "An investigation of the coating/substrate interface of plasma electrolytic oxidation coated aluminum", Surface and Coatings Technology, 280 (2015) 86-91

${ }^{39}$ A. Kossenko, M. Zinigrad "A universal electrolyte for the plasma electrolytic oxidation of aluminum and magnesium", Materials \& Design, 88 (2015) 302-309

${ }^{40}$ G.W. Brindley, C.C. Kao, "Structural and IR Relations Among Brucite-Like Divalent Metal Hydroxides". Phys. Chem. Minerals 10 (1984) 87-191

${ }^{41}$ E. Matykina, R. Arrabal, P. Skeldon, G.E. Thompson, H. Habazaki "Influence of grain orientation on oxygen generation in anodic titania" Thin Solid Films, 516 (8) (2008) 2296-2305

${ }^{42}$ E. Matykina, R. Arrabal, P. Skeldon, G.E. Thompson "Transmission electron microscopy of coatings formed by plasma electrolytic oxidation of titanium" Acta Biomaterialia, 5 (2009) 1356-1366

${ }^{43} \mathrm{G}$. Sundararajan, L.R. Krishna "Mechanisms underlying the formation of thick alumina coatings through the MAO coating technology" Surf. Coatings Technol., 167 (2003) 269-277

${ }^{44}$ Y. Couturier, G. Michard, G. Sarazin "Constantes de formation des complexes hydroxydes de l'aluminium en solution aqueuse de 20 a $70^{\circ} \mathrm{C}^{\prime \prime}$, Geochimica et Cosmochimica Acta 48 (1984) 649-659.

${ }^{45}$ T. Galvão; C. Neves; A. Caetano; F. Maia; D. Mata; E. Malheiro; M. Ferreira; A. Bastos; A. Salak; J. Gomes; J. Tedim; M.G.S. Ferreira "Control of Crystallite and Particle Size in the Synthesis of Layered Double Hydroxides: 
Macromolecular Insights and a Complementary Modelling Tool”, Journal of Colloid and Interface Science, 468 (2016) 86-94

${ }^{46}$ J. Tedim, A. Kuznetsova, A.N. Salak, F. Montemor, D. Snihirova, M. Pilz, M.L. Zheludkevich, M.G.S. Ferreira "Zn-Al layered double hydroxides as chloride nanotraps in active protective coatings", Corrosion Science, 55 (2012) 1-4

${ }^{47}$ X. Lu, S.P. Sah, N. Scharnagl, M. Störmer, M. Starykevich, M. Mohedano, C. Blawert, M.L. Zheludkevich, K.U. Kainer "Degradation behavior of PEO coating on AM50 magnesium alloy produced from electrolytes with clay particle addition" Surface and Coatings Technology, 269 (2015) 155-169

${ }^{48}$ V.R. Capelossi, M. Poelman, I. Recloux, R.P.B. Hernandez, H.G. de Melo, M.G. Olivier "Corrosion protection of clad 2024 aluminum alloy anodized in tartaric-sulfuric acid bath and protected with hybrid sol-gel coating", Electrochim. Acta, 124 (2014), 69-79

${ }^{49}$ M. García-Rubio, M.P. de Lara, P. Ocón, S. Diekhoff, M. Beneke, A. Lavía, I. García "Effect of postreatment on the corrosion behaviour of tartaric-sulphuric anodic films" Electrochim. Acta, 54 (2009) 4789-4800

${ }^{50}$ L. Hao, R. Cheng "Sealing processes of anodic coatings: past, present and future" Met. Finish., 98 (2000) 8-18

${ }^{51}$ S. Shrestha, A. Merstallinger, D. Sickert, B.D. Dunn. „Preliminary evaluation of black coating on AA2219 alloy produced by plasma electrolytic oxidation (PEO) process for space applications" ISMSE (2003) 57-65

${ }^{52}$ S Velu, V Ramkumar, A Narayanan, C. S Swamy "Effect of interlayer anions on the physicochemical properties of zinc-aluminium hydrotalcite-like compounds" Journal of Materials Science 32 (4) (1997) 957-964

${ }^{53}$ D. R. Hines, S. A. Solin, U. Costantino, M. Nocchetti "Physical properties of fixed-charge layer double hydroxides", Phys. Rev. B 61 (2000) 11348

${ }^{54}$ O. Guseva, P. Schmutz, T. Suter, O. von Trzebiatowski, "Modelling of anodic dissolution of pure aluminium in sodium chloride" Electrochimica Acta 54 (2009) 4514-4524.

55 K. D. Ralston, S. Chrisanti, T. L. Young, R. G. Buchheit “Corrosion Inhibition of Aluminum Alloy 2024-T3 by Aqueous Vanadium Species" Journal of The Electrochemical Society, 155 (7) (2008) C350-C359

${ }^{56}$ A.N. Salak, J. Tedim, A.I. Kuznetsova, L.G. Vieira, J.L. Ribeiro, M.L. Zheludkevich, M.G.S. Ferreira, "Thermal Behavior of Layered Double Hydroxide Zn-Al-Pyrovanadate: Composition, Structure Transformations, and Recovering Ability" J. Phys. Chem. C, 117 (8), (2013) 4152-4157

${ }^{57}$ M. lannuzzi, T. Young, G. S. Frankel "Aluminum Alloy Corrosion Inhibition by Vanadates" Journal of the Electrochemical Society, 153(12) (2006) B533-B541

58 P. Visser, A. Lutz, J.M.C. Mol, H. Terryn "Study of the formation of a protective layer in a defect from lithiumleaching organic coating" Progress in Organic Coatings 99 (2016) 80-90 